\title{
Management of Sources and Loads in a Smart Grid
}

\author{
S A. Tadjer ${ }^{1}$, I. Habi ${ }^{1}$, M. El Ganaoui ${ }^{2}$ and S. Angel ${ }^{2}$ \\ ${ }^{1}$ Laboratory Electrification of Industrial Entreprises \\ University M'Hamed Bougara, F.H.C, 35000 Boumerdes (Algeria) \\ Phone/Fax number: +213663 106 200, e-mail: sidahmed79dz@yahoo.fr, habi_idir@yahoo.fr \\ ${ }^{2}$ University of lorraine,University institute of technology Henrie Poincaré of Longwy, LERMAB \& GREEN, (France) \\ 03823962 81, 03823962 90, mohammed.el-ganaoui@univ-lorraine.fr, angel.scipioni@univ-lorraine.fr
}

\begin{abstract}
Currently the targets set by the European Union in terms of decreasing $\mathrm{CO} 2$ emissions, a change in the energy sector rule applies and this translates into more efficient use of renewable energy sources and the need to move towards a smarter grid. For this purpose, integrating the networks of the new information and communications technology will make communicating and will take into account the actions of the players in the electrical system, while ensuring a more efficient delivery of electricity, economically viable and safe.

In this paper an algorithm was validated by virtual simulation, conducted validation shows that the intelligent energy manager allows the erasure of peak demand therefore save on overall energy costs while achieving technical and regulatory constraints. An algorithm of control/command, various scenarios for managing devices connected to networks has been validated by simulation.
\end{abstract}

\section{Key words}

Smart grid; Photovoltaic system; power management, planification, scenario.

\section{Introduction}

The electricity is difficult to store. It is therefore necessary at all times to balance the network, in other words to ensure that the output is equal to the consumption. If the gap between production and consumption increases too much, the network undergoes frequency deviations and damaging voltage network devices and consumers [1]. The consequences can go up to the disconnection of certain branches of the network, or the widespread incident (blackout). It such incidents happened in Algeria on May 3, 2003.

The next iteration will be the "Smart Grids" in other words "Intelligent Electrical Networks" which will be equipped with support systems and real communication [2-4]. As part of the design of the intelligent network is based on decentralization, energy sector restructuring and optimizing its assets [5-7].
The present work aims to facilitate management of the electricity network while integrating renewable energies and manage peak consumption, which are, among others, among the major constraints facing our current network. To do different types of simulation and monitoring/ control scenarios are realized with MATLAB-Simulink.

\section{Issues related to consumption peaks}

The major problem with the electrical network operation is to maintain, permanently, the balance between the available supply and potential demand of electric power, that it can not be stored in large quantities. The parameters influencing the consumption of electricity are essentially meteorological and economic activity. Whenever the temperature drops one degree, consumption rises considerably, in France for example it rises to $2100 \mathrm{MW}$.

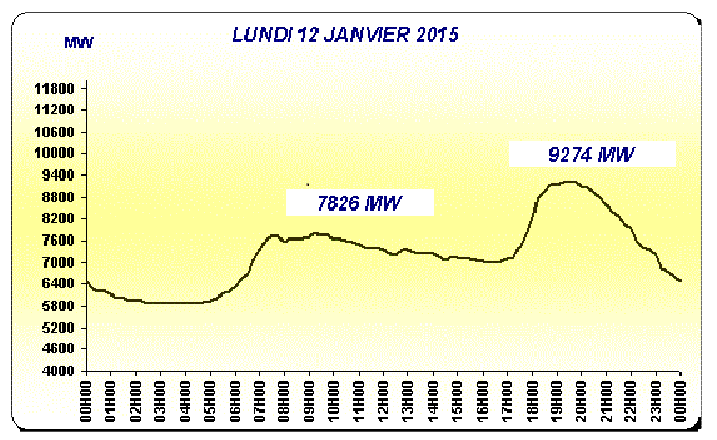

Fig. 1. Example of electrical consumption curve Algerian daily.

Daily consumption curve for winter 2015 has two peaks consumption one in the morning and the second in the evening, as shown in figure 1 on a given day. The daily electricity consumption curve is a reflection, in everyday life, of our lifestyles. Especially in winter, over 24 hours, the power consumption curve shows a peak in the morning, with an increase from 4 am to 8 am, a hollow in the afternoon around $16 \mathrm{~h}$, around $19 \mathrm{~h}$, the evening peak 
and finally a hollow night. Indeed, from 4:00 in the morning, the power consumption increases. By this time the diurnal rhythm life goes, people turn on the light, operate the household appliances for breakfast, some take transport. With the break, power consumption to stabilize and then gradually decreases until $16 \mathrm{~h}$.

\section{Imbalance between supply and demand}

A cutoff phenomenon or shedding can occur due to a general overload and not provided caused by the collapse of the frequency or the collapse of the voltage which leads to exceeding the maximum power lines. These phenomena are illustrated by the blackout (figure 2).

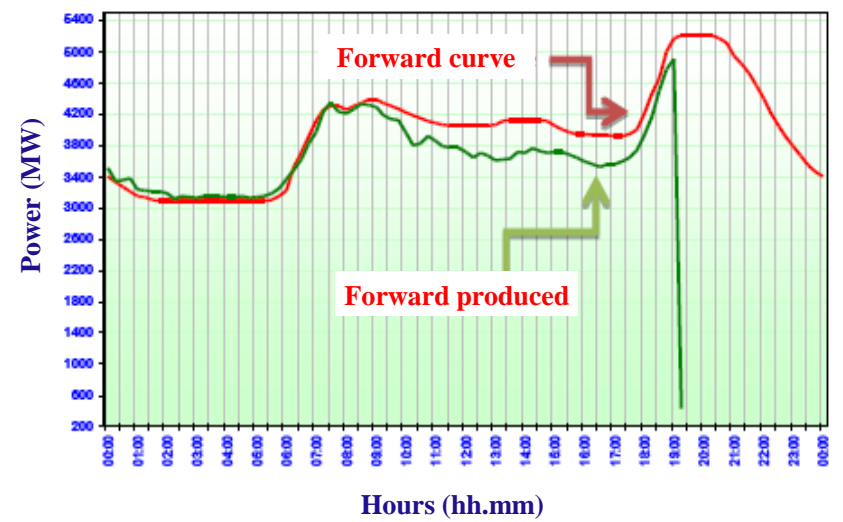

Fig. 2. Load profile of 03/03/2003 before the blackout.

An increased production results in a general lack of voltage on the interconnected grid, the frequency drops sharply, this will be followed by a cascade tripping of the majority of production groups $[8,9]$.

\section{Modeling of the smart grid}

The electrical network we have modeled is described as a single-line diagram in figure 3 which is the following.

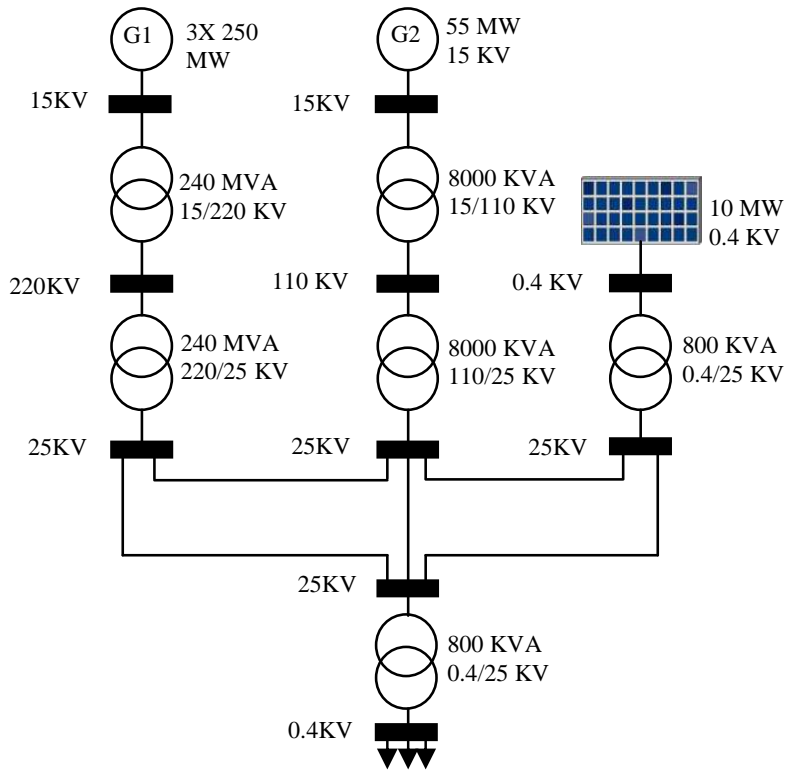

Fig. 3. Schéma unifilaire du réseau étudié.
We have modeled the pattern of our grid, three sources of power generation, which are detailed below:

G1 and G2 are sources representing power plants.

A renewable source of energy necessary for our simulation, which is a photovoltaic field was modeled with Matlab-Simulink. The characteristics of these sources are shown in Table 1:

Table I. - Simulated network settings

\begin{tabular}{|l|l|}
\hline \multicolumn{2}{|c|}{ MAIN POWER GRID } \\
\hline Active Nominal Power & $50 \mathrm{MW}$ \\
\hline Nominal voltage & $15 \mathrm{KV}$ \\
\hline Frequency & $50 \mathrm{~Hz}$ \\
\hline \multicolumn{2}{|c|}{ PHOTOVOLTAIC CHAMP } \\
\hline Number of modules & 5 series / 66 parallel \\
\hline DC Voltage & $500 \mathrm{~V}$ \\
\hline AC Voltage & $25 \mathrm{KV}$ \\
\hline Maximum power AC & $10 \mathrm{MW}$ \\
\hline
\end{tabular}

In figure 4 shows the circuit of the photovoltaic system simulink:

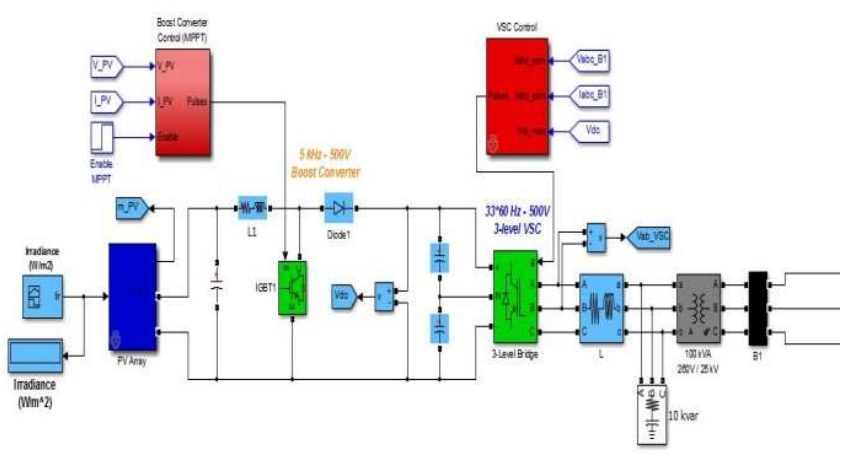

Fig. 4. Electric model of the photovoltaic field in Simulink.

The power generated by the photovoltaic field is related to metrological parameters (irradiance, temperature ...). In this study we pray a daily profile of figure 5 .

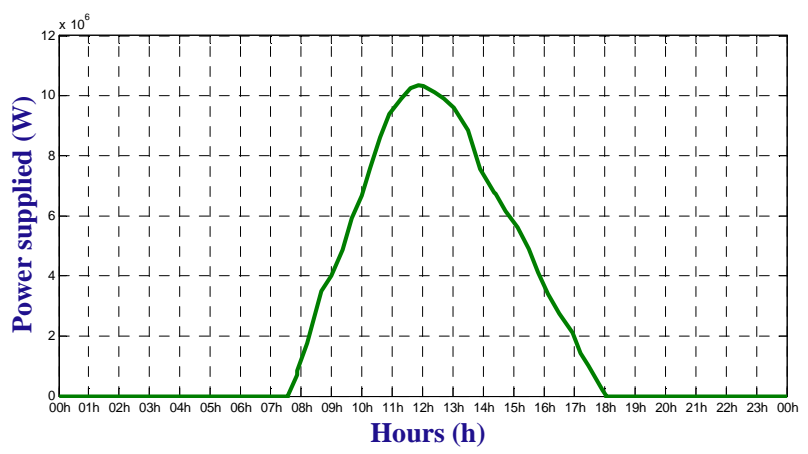

Fig. 5. Power supplied by the PV field.

\section{Modeling of the neighborhood}

For our purposes needed for simulation, a city made up of two expense category 2 and 3 and 30 parts, so that in each of these we integrated 9 houses.

Figure 6 shows the block diagram of a neighborhood reproduced 30 times, so the modeled areas are identical. 


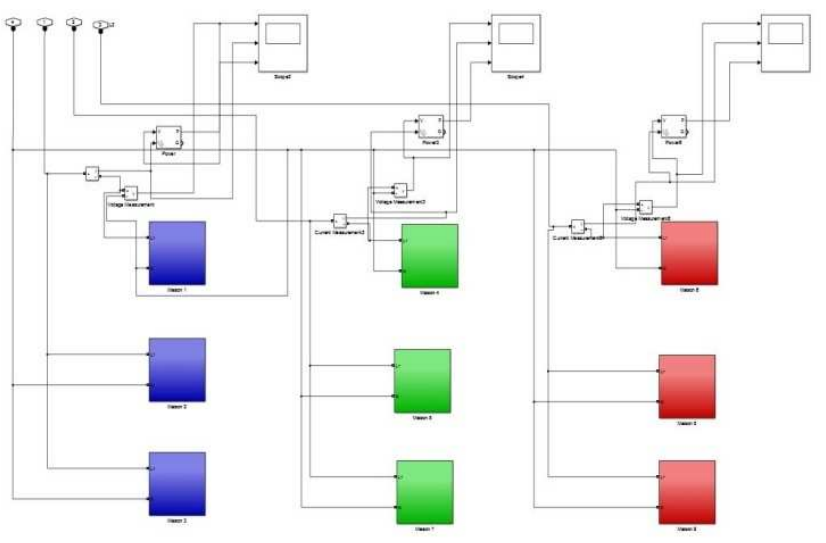

Fig. 6. Block diagram of a neighborhood.

Each neighborhood contains several houses, as each house consists of several modeled equipment (TV, refrigerator, heater ... etc.).

Modeling the consumption of a house that we realized, was based on real consumption curve at the end to have a consumption peak at 20.00, as shown in figure 7 .

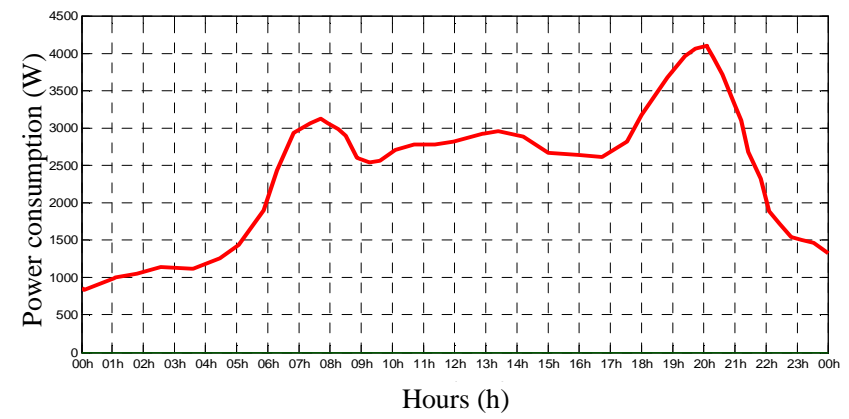

Fig. 7. Profile of a home consumption.

After modeling of our electrical grid, the added value is in a smart algorithm that we have achieved and which will be described in the following.

We created a monitoring and control algorithm, which aims intelligent management of our network [10]. This algorithm is actually a controller of the states of electric power demand so that it is calculated at all times and compared to our sources of renewable and conventional production while focusing our photovoltaic source. This command allows us to stand out several scenarios.

\section{Simulations and discussions}

We achieved a MATLAB-Simulink block diagram consists of a main power network, a backup power system, a photovoltaic field, a city made up of four quarters each new house and two expense category 2 and 3 . We have achieved a controlling / command that is managed by our algorithm. This is shown in figure 8.

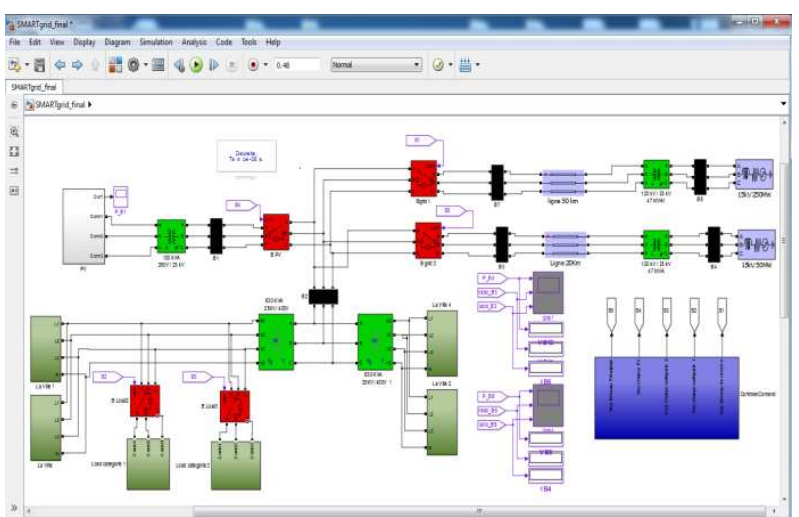

Fig. 8. Profile of a home consumption.

\section{A. Scenarios A: The city load diagram}

In this scenario, we have highlighted the load curve, that is to say the consumption of the city and loads of category 2 and 3, this consumption varies between $23 \mathrm{MW}$ and 41MW (figure9), while the main network debits a power of 52MW; it explains that the two curves overlap, so the load directly consumes the main power network.

The power required by the load is therefore expressed as: $\mathrm{P}_{\text {city }}=\mathrm{P}_{\text {grid }}$.

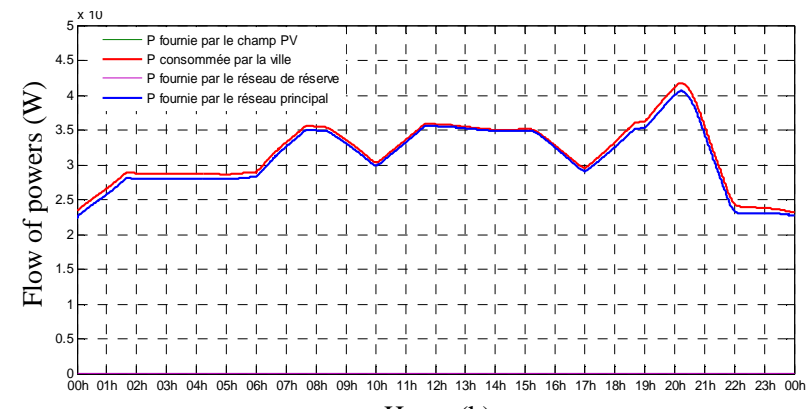

Fig. 9. Flow of powers.

Hours (h)

\section{B. Scenario B: Integration of a photovoltaic field}

The city is fed by the main network for 24 , and the photovoltaic field begins to provide power to about 7:30, then the controller gives a closure order to the photovoltaic circuit breaker $\left(\mathrm{B}_{\mathrm{PV}}=1\right)$ because the demand of the city $\left(\mathrm{P}_{\text {city }}\right)$ exceeds the production of the PV field, therefore where the photovoltaic field only produces an order opening the PV breaker is initiated by the controller $\left(\mathrm{B}_{\mathrm{PV}}\right.$ fields $\left.=0\right)$, this is shown in figure 10 .

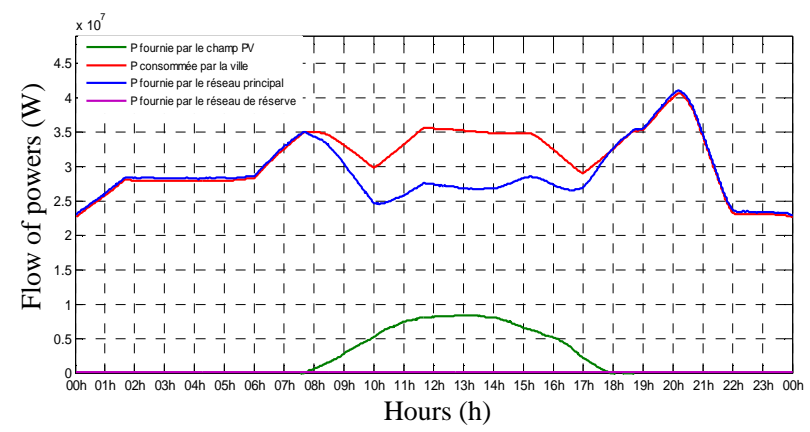

Fig. 10. The power supplied by the PV field for 24 hours. 
Circuit breakers loads of category 2 and 3 are also closed (B2, $3=1)$.

In this case, we want to emphasize that the power consumption is provided by the main grid and the PV field.

\section{Scenario C: peak consumption management}

In this scenario, the city is fed by the main network and the $\mathrm{PV}$ field identically to the previous scenario $\left(\mathrm{B}_{\text {grid }}=1, \mathrm{~B}_{\mathrm{PV}}\right.$ $=1$ between [7h30et $18 \mathrm{~h}]$ ).

Circuit breakers loads of category 2 and 3 will be closed $\left(\mathrm{B}_{2,3}=1\right)$. This is shown in figure 11 .

The power consumed by the city is higher than production of the PV field and the main network, and since the main network provided a maximum of $52 \mathrm{MW}$, the city will not be fed in this case, which will cause a blackout. The controller then provides a closure order to the backup system circuit breaker to avoid this problem $\left(B_{\text {reserve }}=1\right)$.

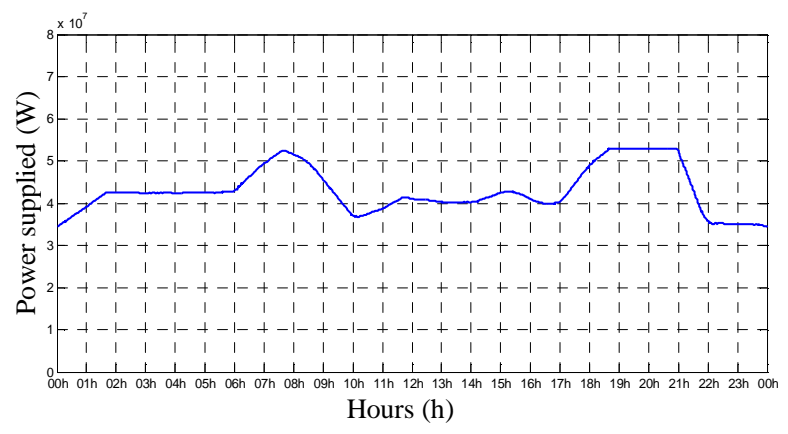

Fig. 11. The power supplied by the main network for 24 hours.

The simulation of the 2 nd scenario had the interest to incorporate the production-based PV array and according to the results we have seen a decline in the appeal of the energy supplied by the main network this during the period of production PV field.

The third scenario simulation has shown that during a consumption increase of the city during the weekend, the controller gives a command to disconnect loads, this is to avoid a disrupted supply of the city, or effect shedding.

The simulation of the fourth scenario was designed to control the backup system by switching its circuit breaker when the consumption of the city exceeds the production of the PV field and that of the main grid during peak consumption, so while this increased demand the backup system takes care of feeding the difference between the production of the main network and consumption.

From these scenarios, showed that the main network, which is actually a gas plant, has been reduced due to the integration of a photovoltaic field, we also demonstrated that the network control Reserve and expenses of disconnection is done instantly, which therefore has the benefit of avoiding the effects of load shedding and blackouts, hence, so the interest of a smart grid, which perfectly meets all these expectations.

The algorithm we developed enabled the integration of renewable energies, smoothing the peak power and control of consumers, who are fillers, the perfect definition of a smart grid.

\section{Conclusion}

According to the results of various simulations using MATLAB/Simulink, highlighted the benefits of a flexible electrical network, controlled and therefore intelligent, the load management including advanced consumption and centralized production (main system and backup system) and decentralized (photovoltaic field).

The simulation of the first scenario was to demonstrate the city's consumption curve and expenses in categories 2 and 3 , driven by our core network only.

\section{Acknowledgement}

The author wish to thank all colleagues who previously provided technical support.

\section{References}

[1] J. Fernandez Orjuela, "Intégration des Véhicules Electriques dans le réseau électrique résidentiel : impact sur le déséquilibre et stratégies V2G innovantes", Electric power. Université de Grenoble, 2014. French.

[2] J. Gao, Y. Xiao, J L. Wei Liang and C.L. Philip Chen, "A survey of communication/networking in Smart Grids", The international Journal of future génération computer systems, vol $28, n^{\circ} 2$, fév. 2012

[3] J. Lagorse, D. Paire, and A. Miraoui, "A multi-agent system for energy management of distributed power sources", Renewable Energy, 35(1), pp. 174-182, 2010.

[4] S.Alepuz, et al, "Control Strategies Based on Symmetrical Components for Grid-Connected Converters Under Voltage Dips", IEEE Transactions on Industrial Electronics, 56, no. 6, pp. 2162-2173, 2009.

[5] S. Ramchurn, P. vytelingum, A.roggers and N.jennings, "Putting the s-marts into the smart grid: a grand challenge for artificial intelligence," commun. ACM, vol.55,no.4, apr.2014

[6] J. R. Pillai, P. Thogersen, J. Moller and B. Bak-Jensen, "Integration of electric vehicles in low voltage danish distribution grids", in Power and Energy Society General Meeting, IEEE, pp. 1-8, 2012.

[7] A. Carvallo, "The Advanced Smart Grid: Edge Power Driving Sustainability", Artech House, June, 2011.

[8] R. Badreddine, Gestion énergétique optimisée pour un bâtiment intelligent multi-sources multi-charges : différents principes de validations", Universite de Grenoble, 2012.

[9] E. Soren, P. Elbert and L. Guzzella, "Battery State-ofHealth Perceptive Energy Management for Hybrid Electric Vehicles ", IEEE Transactions on vehicular technology, 61, no. 7, 2012.

[10] M. Chenafi, S. BougElghoul, "Gestion des Sources et des Charges Dans un Réseau Electrique Intelligent "Smart Grid»", Master thesis, university of Boumerdes, Algeria, 2015. 